\title{
Inequality, Bipolarization, and Tax Progressivity *
}

\author{
Oriol Carbonell-Nicolau ${ }^{\dagger} \quad$ Humberto Llavador ${ }^{\ddagger}$
}

June 2021

\begin{abstract}
The steady rise in income and wealth inequality in the last four decades, together with the evolution of a vanishing middle class, has raised concerns about potentially pernicious effects of these trends on social stability and economic growth. This paper evaluates the possibility of designing tax systems aimed at reducing income inequality and bipolarization. Using two fundamentally different metrics, the relative Lorenz preorder popularized by Atkinson (1970) to measure inequality, and the relative bipolarization preorder put forth in Chakravarty $(2009,2015)$ to measure bipolarization, we provide a unified foundation of tax progressivity whereby, roughly, taxes are progressive if and only if they are inequality reducing if and only if they are bipolarization reducing. The details of this characterization vary depending on whether or not labor supply is responsive to taxation.
\end{abstract}

Keywords: shrinking middle class; progressive taxation; income bipolarization; income inequality; incentive effects of taxation.

JEL classifications: D63, D71.

\section{Introduction}

The so-called 'Great Divergence,' i.e., the period, starting in the late 1970s, during which a steady and significant increase in income inequality has been observed in the US, has spurred not only a renewed interest in inequality (see, e.g., Atkinson, 2015; Milanovic, 2016; Piketty, 2014), but also a growing concern about the disappearance of the middle class (see, e.g., Birdsall et al., 2000; Pew Research Center, 2015, 2017; Fortune, 2018). Several authors have emphasized the importance of the size of the middle class along a number of economic and social dimensions (see, e.g., Banerjee and Duflo, 2008), and as a determinant of economic growth (Easterly, 2001). The middle class is a key provider of skilled labor and, directly or indirectly, of tax revenue. It also transmits 'middle class values' associated with increased savings, more education, better health care, better infrastructure, better economic policies, less political instability, and more democracy (Birdsall, 2010; Duclos and Taptué, 2015). As Duclos and Taptué (2015, p. 319) argue, "a larger-sized middle class is associated

\footnotetext{
*We thank two anonymous referees for their comments. We have no relevant or material financial interests that relate to the research described in this paper.

${ }^{\dagger}$ Department of Economics, Rutgers University, 75 Hamilton Street, New Brunswick, NJ 08901, USA. E-mail: carbonell-nicolau@rutgers. edu.

¥Universitat Pompeu Fabra and Barcelona GSE, R. Trias Fargas 25-27, 08005 Barcelona, Spain. E-mail: humberto. Ilavador@upf .edu. Llavador acknowledges financial support from the Spanish Ministry of Economy and Competitiveness through the Severo Ochoa Programme for Centers of Excellence in R\&D (SEV-2015-0563), the AEI/FEDER-UE (PGC2018-096370-B-100) and the AEI/FEDER-EU (ECO2017-89240-P).
} 
with societies with lesser poles at each extreme of the income distribution, thus facilitating political and social harmony and more stable and stronger economic development."

Since the 1990s, social scientists have viewed the size of the middle class as being intimately related to the concept of bipolarization (Wolfson, 1994; Deutsch et al., 2013). ${ }^{1}$ According to Wolfson (1994), a more bipolarized income distribution is one that is more spread out from the middle, so that there are fewer individuals with middle level incomes. Usually this spreading out goes hand in hand with a tendency towards bimodality. This is because a smaller middle class is associated with greater separateness of the bottom and top halves of the income distribution and with greater distances between groups. ${ }^{2}$

Although both bipolarization and inequality relate to the distribution of income and tend to be normatively regrettable, there are conceptual differences between them. Whereas inequality relates to the overall dispersion of the distribution, bipolarization concentrates on the income distribution of two focal, or polar, modes on both sides of the median. ${ }^{3}$ For instance, progressive income transfers (i.e., transfers from rich to poor individuals) across the median income reduce both inequality and bipolarization, but same-side progressive transfers (i.e., transfers between individuals whose incomes lie either above or below the median) cause inequality and polarization to move in opposite directions (Wolfson, 1994; Foster and Wolfson, 2010).

This paper provides a normative rationale for progressivity based on principles of equality and depolarization. It is shown that, even though inequality and polarization are fundamentally different concepts, a unified foundation of tax progressivity can be obtained whereby, roughly, taxes are progressive if and only if they are inequality reducing if and only if they are bipolarization reducing.

We consider general spaces of continuous, piecewise linear, nondecreasing, and income rank-preserving tax schedules, and study both the case of exogenous and the case of endogenous income, as results tend to vary depending on whether or not labor supply is responsive to taxation.

The results on inequality rely on Carbonell-Nicolau and Llavador (2018, forthcoming), which study the link between inequality and progressive taxation, extending the classical result of Jakobsson (1976) and Fellman (1976) to the case of endogenous income. Using the standard relative Lorenz criterion, Carbonell-Nicolau and Llavador (2018, forthcoming) show that marginal rate progressivity-in the sense of increasing marginal tax rates on income-is a necessary condition for tax structures to be inequality reducing; they also provide necessary and sufficient conditions on preferences under which various classes of progressive taxes are inequality reducing.

The literature offers several tools for ordering distributions over families of indices that exhibit an ethical preference for the middle class (Wolfson, 1994; Wang and Tsui, 2000; Bossert and Schworm, 2008; Foster and Wolfson, 2010; Chakravarty, 2009, 2015). The proposed measures share two basic axioms, called increased spread and increased bipolarity. Increased spread implies an unambiguous movement away from the median, with rich

\footnotetext{
${ }^{1}$ In fact, the literature on bipolarization developed hand in hand with the continuous decline in the size of the middle class in the US and the UK since the 1980s (Wolfson, 1994; Jenkins, 1995).

${ }^{2}$ In the literature, the notion of bipolarization is distinguished from multipolarization measures (such as those in Esteban and Ray (1994) and Duclos, Esteban and Ray (2004)), which do not capture the size of the middle class. Despite their different focus, most polarization measures agree with two main principles: polarization declines with "intra-group" dispersion and increases with "inter-group" dispersion (Esteban and Ray, 2012). For a detailed comparison of polarization measures, see Esteban and Ray (2012), Duclos and Taptué (2015) and Chakravarty (2009, 2015).

${ }^{3}$ As noted by Aaberge and Atkinson (2013), the median has become an increasingly important point of reference in studies of income distribution.
} 
individuals becoming richer and poor individuals becoming poorer. Increased bipolarity refers to the clustering of incomes above and below the median. Both increased spread and increased bipolarity increase polarization. ${ }^{4}$ This paper considers the notion of bipolarization put forth in Chakravarty (2009, 2015), which is based on an incomplete preorder akin to the relative Lorenz criterion. Chakravarty's ordering serves our needs in that it allows for comparisons of distributions with different medians. When comparing distributions with the same median, this ordering is equivalent to the polarization ordering in Foster and Wolfson (2010)—or its equivalent formulation in Wang and Tsui (2000)—and the order $\geq_{0}$ in Theorem 1 of Bossert and Schworm (2008). ${ }^{5}$

The first main result, Corollary 1, asserts that, when incomes are exogenous (or relatively unresponsive to taxation), taxes are average-rate progressive if and only if they are inequality reducing if and only if they are bipolarization reducing. A similar result, Corollary 3 , is derived for the case of endogenous income, establishing the equivalence between inequality and bipolarization reducing tax systems, and identifying necessary and sufficient conditions on social preferences under which various classes of marginal-rate progressive tax schedules are inequality and bipolarization reducing.

The paper is organized as follows. Section 2 introduces the two basic normative principles of taxation, based on measures of inequality and bipolarization. The main results are presented in Section 3, where the cases of exogenous and endogenous income are considered in turn (in Section 3.1 and Section 3.2, respectively). The concluding section, Section 4, discusses avenues for further research.

\section{Two normative principles of taxation}

This section introduces the principles of taxation used in this paper to characterize tax progressivity. The formulation of these principles is based on the comparison of income distributions.

An income distribution is a vector $\boldsymbol{z}=\left(z_{1}, \ldots, z_{n}\right)$ in $\mathbb{R}_{++}^{n}$ with its coordinates arranged in increasing order, i.e., $z_{1} \leq \cdots \leq z_{n} ;{ }^{6}$ here, for each $i, z_{i}$ represents the income of individual $i$, and $n$ is a fixed, but otherwise arbitrary, natural number representing the size of the population. The set of all income distributions is denoted by $\mathcal{Z}_{n} \cdot{ }^{7}$ Throughout the sequel, in the main text, we confine attention to the case when $n$ is odd, and relegate the treatment for $n$ even to the Appendix.

A tax schedule is a continuous and nondecreasing map $T: \mathbb{R}_{+} \rightarrow \mathbb{R}$ that assigns to each income level $z \in \mathbb{R}_{+}$a tax liability $T(z)$ and has the properties that $T(z) \leq z$ for each $z \in \mathbb{R}_{+}$ and the map $z \mapsto z-T(z)$ is nondecreasing (i.e., $T$ is order-preserving). A negative tax liability represents a subsidy.

The set of all tax schedules is denoted by $\mathscr{T}$.

\subsection{Income inequality}

The first principle poses that taxes should reduce income inequality, regardless of the income distribution they are applied to, and is based on the relative Lorenz preorder, popularized by Atkinson (1970) as a measure of inequality.

\footnotetext{
${ }^{4}$ Observe that while increased spread also increases inequality, increased bipolarity could result from an egalitarian transfer between individuals on the same side of the median (Chakravarty, 2009).

${ }^{5}$ Bossert and Schworm (2008) call it a 'two-group polarization measure.'

${ }^{6}$ The assumption that each $z_{i}$ is positive is not necessary. It can be replaced by the requirement that median incomes be positive.

${ }^{7}$ None of the results of this paper would be altered if the set of all income distributions were defined as $\cup_{k=1}^{\infty} \mathcal{Z}_{k}$.
} 
Given two income distributions, $\boldsymbol{z}=\left(z_{1}, \ldots, z_{n}\right)$ and $\boldsymbol{z}^{\prime}=\left(z_{1}^{\prime}, \ldots, z_{n}^{\prime}\right)$, in $\mathcal{Z}_{n}$, the relative Lorenz preorder $\succcurlyeq_{L}$ is defined by

$$
\left.\boldsymbol{z}^{\prime} \succcurlyeq_{L} \boldsymbol{z} \Longleftrightarrow \quad \forall m \in\{1, \ldots, n\}: \frac{\sum_{i=1}^{m} z_{i}^{\prime}}{\sum_{i=1}^{n} z_{i}^{\prime}} \geq \frac{\sum_{i=1}^{m} z_{i}}{\sum_{i=1}^{n} z_{i}}\right] .
$$

In words, $\boldsymbol{z}^{\prime}$ Lorenz dominates $\boldsymbol{z}$.

When incomes are exogenous, the principle of 'inequality reducing taxation' is formulated as follows.

Definition 1. A tax schedule $T$ in $\mathscr{T}$ is income inequality reducing (iir) if

$$
\left(z_{1}-T\left(z_{1}\right), \ldots, z_{n}-T\left(z_{n}\right)\right) \succcurlyeq_{L} \boldsymbol{z}, \quad \text { for all } \boldsymbol{z}=\left(z_{1}, \ldots, z_{n}\right) \in \mathcal{Z}_{n}
$$

i.e., if the post-tax income distribution induced by $T,\left(z_{1}-T\left(z_{1}\right), \ldots, z_{n}-T\left(z_{n}\right)\right)$, Lorenz dominates $\boldsymbol{z}$ for all income distributions $\boldsymbol{z} \in \mathcal{Z}_{n}$.

When incomes are determined endogenously, the definition of an inequality reducing tax schedule requires additional terminology. The analogue of Definition 1 , adapted to allow for labor supply responses to income taxation, is presented in Section 3.2.

\subsection{Income bipolarization}

The second principle asserts that taxes should reduce income bipolarization, regardless of the income distribution they are applied to. This paper considers the notion of bipolarization put forth in Chakravarty (2009, 2015), which is based on an incomplete preorder akin to the relative Lorenz criterion. Chakravarty's ordering serves our needs in that it allows for comparisons of distributions with different medians.

We now formulate Chakravarty's bipolarization ordering for income distributions of a fixed population size $n$, where $n$ is odd.

The median of an income distribution $\boldsymbol{z}=\left(z_{1}, \ldots, z_{n}\right)$ is denoted by $m(\boldsymbol{z})$. When $n$ is odd, $m(\boldsymbol{z})$ is the $\left(\frac{n+1}{2}\right)$-th coordinate in $\left(z_{1}, \ldots, z_{n}\right)$, and so in this case we may set $m(\boldsymbol{z})=: z_{m}$, where $m:=\frac{n+1}{2}$.

The relative bipolarization preorder of Chakravarty $(2009,2015)$, denoted by $\succcurlyeq_{R B}$, is defined, on $\mathcal{Z}_{n}$, as follows. Given two income distributions $\boldsymbol{z}$ and $\boldsymbol{z}^{\prime}$ in $\mathcal{Z}_{n}$ ( $n$ odd), $\boldsymbol{z}^{\prime} \succcurlyeq_{R B} \boldsymbol{z}$ with the interpretation that ' $\boldsymbol{z}$ ' is more polarized than $\boldsymbol{z}$ '-if and only if

$$
R B\left(\boldsymbol{z}^{\prime}, \alpha\right) \geq R B(\boldsymbol{z}, \alpha), \quad \text { for all } \alpha \in[0,1],
$$

where, given $\alpha \in[0,1]$ and given any income distribution $z \in \mathcal{Z}_{n}, R B(\boldsymbol{z}, \alpha)$ represents the normalized aggregate deviation from the median income, i.e.:

$$
R B(\boldsymbol{z}, \alpha):= \begin{cases}\frac{1}{n z_{m}} \sum_{j \leq i<m}\left(z_{m}-z_{i}\right) & \text { if } \alpha=\frac{j}{n} \text { for some } j \in\{1, \ldots, m-1\}, \\ \frac{1}{n z_{m}} \sum_{m \leq i \leq j}\left(z_{i}-z_{m}\right) & \text { if } \alpha=\frac{j}{n} \text { for some } j \in\{m, \ldots, n\}, \\ 1 & \text { if } \alpha=0,\end{cases}
$$

and

$$
R B(\boldsymbol{z}, \alpha):=\lambda R B\left(\boldsymbol{z}, \frac{j}{n}\right)+(1-\lambda) R B\left(\boldsymbol{z}, \frac{j+1}{n}\right)
$$

if $\alpha=\lambda\left(\frac{j}{n}\right)+(1-\lambda)\left(\frac{j+1}{n}\right)$, where $\lambda \in(0,1)$ and $j \in\{0,1, \ldots, n-1\}$. 
The preorder $\succcurlyeq_{R B}$ is axiomatized as a bipolarization measure in Chakravarty (2009, Theorem 4.3). ${ }^{8}$

When incomes are exogenous, the principle of 'bipolarization reducing taxation' is formulated as follows.

Definition 2. A tax schedule $T$ in $\mathscr{T}$ is income bipolarization reducing (bpr) if

$$
\left(z_{1}-T\left(z_{1}\right), \ldots, z_{n}-T\left(z_{n}\right)\right) \preccurlyeq_{R B} \boldsymbol{z}, \quad \text { for all } \boldsymbol{z}=\left(z_{1}, \ldots, z_{n}\right) \in \mathcal{Z}_{n},
$$

i.e., if the post-tax income distribution induced by $T,\left(z_{1}-T\left(z_{1}\right), \ldots, z_{n}-T\left(z_{n}\right)\right)$, is less polarized than $\boldsymbol{z}$ for all income distributions $\boldsymbol{z} \in \mathfrak{Z}_{n}$.

Remark 1. The preorder $\succcurlyeq_{R B}$ differs from the Lorenz preorder. This is a consequence of the fact, pointed out by Foster and Wolfson (2010), that the Lorenz preorder differs from the Foster-Wolfson preorder because the former violates (unlike the latter) the increased bipolarity axiom introduced in Foster and Wolfson (2010). Indeed, the increased bipolarity axiom poses that progressive transfers between individuals whose incomes lie either above or below the median income of a distribution result in higher bipolarization. Since any progressive transfer leads to an unambiguous decrease in inequality, as measured by the Lorenz pre-order, bipolarization and inequality move in opposite directions when same-side transfers occur (Wolfson, 1994).

Adapting Definition 2 to the case of endogenous income requires additional terminology. Such adaptation is provided in Section 3.2.

\section{Characterizations of progressivity}

A prominent normative rationale for progressive income taxation is based on the principle of equality in Definition 1. It has been shown that, roughly, taxes are progressive if and only if they are inequality reducing. The details of this result vary depending on whether or not labor supply is responsive to taxes. This section recaptures the extant results linking progressivity and inequality and furnishes new characterizations of progressive income taxation based on the bipolarization principle in Definition 2. It is shown that the two principles of taxation introduced in Section 2 (Definition 1 and Definition 2) are equivalent. In addition, they can be characterized in terms of progressive income taxation. Thus, even though inequality and bipolarization are fundamentally different concepts, a unified foundation of progressivity can be obtained whereby, roughly, taxes are progressive if and only if they are inequality reducing if and only if they are bipolarization reducing.

\subsection{Exogenous income}

The first characterization of progressive income taxation based on the principle of equality formulated in Definition 1 is given in the seminal works of Jakobsson (1976) and Fellman (1976). ${ }^{9}$ These papers restrict attention to the case when (pre-tax) income is unresponsive to taxes.

Definition 3. A tax schedule $T \in \mathscr{T}$ is average-rate progressive if it exhibits nondecreasing average tax rates on income, i.e., if the map $z \mapsto \frac{T(z)}{z}$ defined on $\mathbb{R}_{++}$is nondecreasing.

\footnotetext{
${ }^{8}$ See also Chakravarty (2015, Theorem 2.3). Chakravarty shows that $\boldsymbol{z}^{\prime} \succcurlyeq_{R B} \boldsymbol{z}$ if and only if $P\left(\boldsymbol{z}^{\prime}\right)>P(\boldsymbol{z})$ for all relative bipolarization indices $P$ satisfying the axioms of Increased Spread, Increased Bipolarity, and Symmetry (anonymity). The order $\succcurlyeq_{R B}$ is a superset of the order $\succeq_{0}$ considered in Bossert and Schworm (2008), which must be contained in all bipolarization orderings satisfying Increased Spread and Increased Bipolarity (see Bossert and Schworm, 2008, Theorem 1).

${ }^{9}$ See also Le Breton et al. (1996, Proposition 3.1).
} 
The set of all average-rate progressive tax schedules in $\mathscr{T}$ is denoted by $\mathscr{T}_{\text {a-prog. }}$. The set of all iir tax schedules in $\mathscr{T}$ (Definition 1 ) is denoted by $\mathscr{T}_{\text {iir }}$.

Theorem 1 (Jakobsson (1976) and Fellman (1976)). $\mathscr{T}_{\text {iir }}=\mathscr{T}_{\text {a-prog. }}{ }^{10}$

As it turns out, average-rate tax progressivity can also be rationalized via the bipolarization principle formulated in Definition 2. Let $\mathscr{T}_{b p r}$ represent the set of all tax schedules in $\mathscr{T}$ that are bpr.

Theorem 2. $\mathscr{T}_{a-p r o g}=\mathscr{T}_{b p r}$.

Proof. [ $\mathscr{T}_{\text {a-prog }} \supseteq \mathscr{T}_{b p r}$.] Suppose that $T \in \mathscr{T}_{b p r}$ and $T \notin \mathscr{T}_{\text {a-prog. }}$. Because $T$ is not average-rate progressive, there exist $\hat{\boldsymbol{z}} \in \mathcal{Z}_{n}$ and $\hat{z}_{i}, \hat{z}_{j}$ with $\hat{z}_{i}<\hat{z}_{j}$ such that

$$
\frac{\hat{z}_{j}-T\left(\hat{z}_{j}\right)}{\hat{z}_{j}}>\frac{\hat{z}_{i}-T\left(\hat{z}_{i}\right)}{\hat{z}_{i}} \text {. }
$$

Now choose an income distribution $\boldsymbol{z}=\left(z_{1}, \ldots, z_{n}\right)$ with $z_{m-1}:=\hat{z}_{i}<\hat{z}_{j}=: z_{m}$, where $m:=\frac{n+1}{2}$, so that $z_{m}$ is the median income. (Recall that $n$ is odd.) Then,

$$
\begin{aligned}
R B\left(\left(z_{1}-T\left(z_{1}\right), \ldots, z_{n}-T\left(z_{n}\right)\right), \frac{m-1}{n}\right) & =\frac{\left(z_{m}-T\left(z_{m}\right)\right)-\left(z_{m-1}-T\left(z_{m-1}\right)\right)}{n\left(z_{m}-T\left(z_{m}\right)\right)} \\
& =\frac{1}{n}\left(1-\frac{z_{m-1}-T\left(z_{m-1}\right)}{z_{m}-T\left(z_{m}\right)}\right) \\
& =\frac{1}{n}\left(1-\frac{\hat{z}_{i}-T\left(\hat{z}_{i}\right)}{\hat{z}_{j}-T\left(\hat{z}_{j}\right)}\right) \\
& >\frac{1}{n}\left(1-\frac{\hat{z}_{i}}{\hat{z}_{j}}\right) \\
& =\frac{1}{n}\left(1-\frac{z_{m-1}}{z_{m}}\right) \\
& =\frac{1}{n}\left(\frac{z_{m}-z_{m-1}}{z_{m}}\right) \\
& =R B\left(\boldsymbol{z}, \frac{m-1}{m}\right)
\end{aligned}
$$

where the inequality uses (3), contradicting the initial assumption that $T \in \mathscr{T}_{b p r}$.

$\left[\mathscr{T}_{\text {a-prog }} \subseteq \mathscr{T}_{\text {bpr. }}\right.$. Let $T \in \mathscr{T}_{\text {a-prog. }}$. We must show that $T \in \mathscr{T}_{b p r}$. Take $\boldsymbol{z}=\left(z_{1}, \ldots, z_{n}\right) \in \mathcal{Z}_{n}$ and define $b_{i}:=\frac{z_{i}-T\left(z_{i}\right)}{z_{i}}$ for $i \in\{1, \ldots, n\}$.

Average-rate progressivity implies that $b_{i}$ is nonincreasing in $i$. Observe that we can write

$$
\left|\frac{\left(z_{m}-T\left(z_{m}\right)\right)-\left(z_{i}-T\left(z_{i}\right)\right)}{n\left(z_{m}-T\left(z_{m}\right)\right)}\right|=\frac{1}{n}\left|1-\frac{b_{i}}{b_{m}} \frac{z_{i}}{z_{m}}\right|, \quad i \in\{1, \ldots, n\} .
$$

For all $i<m, 1>\frac{b_{i}}{b_{m}} \frac{z_{i}}{z_{m}} \geq \frac{z_{i}}{z_{m}}$. Therefore,

$$
\left|\frac{\left(z_{m}-T\left(z_{m}\right)\right)-\left(z_{i}-T\left(z_{i}\right)\right)}{n\left(z_{m}-T\left(z_{m}\right)\right)}\right|=\frac{1}{n}\left(1-\frac{b_{i}}{b_{m}} \frac{z_{i}}{z_{m}}\right) \leq \frac{1}{n}\left(1-\frac{z_{i}}{z_{m}}\right)=\frac{z_{m}-z_{i}}{n z_{m}} .
$$

\footnotetext{
${ }^{10}$ A proof of Theorem 1 can be found in Le Breton et al. (1996, Proposition 3.1), which is stated for a bigger space of income distributions, namely the set $\bigcup_{n=1}^{\infty} \mathcal{Z}_{n}$, but the proof in Le Breton et al. (1996) works for $\mathcal{Z}_{n}$ (for fixed $n$ ).
} 
Similarly, for all $i>m, 1<\frac{b_{i}}{b_{m}} \frac{z_{i}}{z_{m}} \leq \frac{z_{i}}{z_{m}}$ and, hence,

$$
\left|\frac{\left(z_{m}-T\left(z_{m}\right)\right)-\left(z_{i}-T\left(z_{i}\right)\right)}{n\left(z_{m}-T\left(z_{m}\right)\right)}\right|=\frac{1}{n}\left(\frac{b_{i}}{b_{m}} \frac{z_{i}}{z_{m}}-1\right) \leq \frac{1}{n}\left(\frac{z_{i}}{z_{m}}-1\right)=\frac{z_{i}-z_{m}}{n z_{m}} .
$$

From (4) and (5), we conclude that

$$
R B\left(\left(z_{1}-T\left(z_{1}\right), \ldots, z_{n}-T\left(z_{n}\right)\right), \alpha\right) \leq R B(\boldsymbol{z}, \alpha), \quad \text { for all } \alpha \in[0,1],
$$

and consequently

$$
\left(z_{1}-T\left(z_{1}\right), \ldots, z_{n}-T\left(z_{n}\right)\right) \preccurlyeq R B \boldsymbol{z} .
$$

Since $\boldsymbol{z}$ was arbitrary in $\mathcal{Z}_{n}$, we conclude that $T \in \mathscr{T}_{b p r}$.

Theorem 1 and Theorem 2 combined immediately give the following.

Corollary 1. $\mathscr{T}_{i i r}=\mathscr{T}_{b p r}=\mathscr{T}_{a-p r o g}$.

Corollary 1 characterizes progressive income taxation in terms of the two taxation principles considered in this paper. It asserts that, when incomes are exogenous (or relatively unresponsive to taxation), taxes are average-rate progressive if and only if they are inequality reducing if and only if they are bipolarization reducing.

\subsection{Endogenous income}

To allow for potential disincentive effects of taxation on work effort, we adopt the standard Mirrlees model (Mirrlees, 1971). The description of the setup follows Carbonell-Nicolau and Llavador (2018) closely.

The utility function $u: \mathbb{R}_{+} \times[0,1] \rightarrow \mathbb{R}$, defined over consumption-labor pairs $(c, l) \in$ $\mathbb{R}_{+} \times[0,1]$, is assumed continuous with $u(\cdot, l)$ strictly increasing in $c$ for each $l \in[0,1)$ and $u(c, \cdot)$ strictly decreasing in $l$ for each $c>0$. In addition, we assume that $u$ is strictly quasiconcave on $\mathbb{R}_{+_{+}} \times[0,1)$ and twice continuously differentiable on $\mathbb{R}_{++} \times(0,1)$, and that there exists $l>0$ such that $u(c, l)>u(0)$ whenever $c>0 .{ }^{11}$

For $(c, l) \in \mathbb{R}_{++} \times(0,1)$, let

$$
\operatorname{MRS}(c, l):=-\frac{u_{l}(c, l)}{u_{c}(c, l)}
$$

denote the marginal rate of substitution of labor for consumption, where

$$
u_{c}(c, l):=\frac{\partial u(c, l)}{\partial c} \text { and } u_{l}(c, l):=\frac{\partial u(c, l)}{\partial l} .
$$

The following assumptions will be maintained for each $c>0$ :

$$
\lim _{l \rightarrow 1^{-}} \operatorname{MRS}(c, l)=+\infty \text { and } \lim _{l \rightarrow 0^{+}} \operatorname{MRS}(c, l)<+\infty .
$$

The first condition states that the compensation required by an individual for an extra unit of working time tends to infinity as the agent's leisure time approaches zero. The second condition is a mild finiteness condition on the marginal rate of substitution of labor for consumption.

The set of all utility functions satisfying the above conditions is denoted by $\mathscr{U}$.

An ability distribution is a vector $\boldsymbol{a}=\left(a_{1}, \ldots, a_{n}\right)$ in $\mathbb{R}_{++}^{n}$ such that the coordinates in $\boldsymbol{a}$ are arranged in increasing order, i.e., $a_{1} \leq \cdots \leq a_{n}$; here, for each $i, a_{i}$ represents the ability level of agent $i$. Let $\mathscr{A}_{n}$ represent the set of all ability distributions.

\footnotetext{
${ }^{11}$ The last assumption is only needed for consistency in the definition of the bipolarization preorder, and it merely implies that, in the absence of taxation, individuals consume a positive amount.
} 
An agent of ability $a>0$ who chooses $l \in[0,1]$ units of labor and faces a tax schedule $T \in \mathscr{T}$ consumes $c=a l-T(a l)$ units of the good and derives a utility of $u(c, l)$. Thus, the agent's problem is

$$
\max _{l \in[0,1]} u(a l-T(a l), l) .
$$

A solution function is a map $l^{u}: \mathbb{R}_{++} \times \mathscr{T} \rightarrow[0,1]$ such that $l^{u}(a, T)$ is a solution to (6) for each $(a, T) \in \mathbb{R}_{++} \times \mathscr{T}$. A solution function $l^{u}$ induces pre-tax and post-tax income functions, $y^{u}: \mathbb{R}_{++} \times \mathscr{T} \rightarrow \mathbb{R}_{+}$and $x^{u}: \mathbb{R}_{++} \times \mathscr{T} \rightarrow \mathbb{R}_{+}$respectively, defined by

$$
y^{u}(a, T):=a l^{u}(a, T) \text { and } x^{u}(a, T):=a l^{u}(a, T)-T\left(a l^{u}(a, T)\right) .
$$

We write $y^{u}(a, 0)$ and $x^{u}(a, 0)$ to denote, respectively, the pre-tax and post-tax incomes of an $a$-type in the absence of taxation, i.e., for an identically zero tax schedule $T \equiv 0$.

Given $a>0$, let $U^{a}: \mathbb{R}_{+} \times[0, a] \rightarrow \mathbb{R}$ be defined by $U^{a}(c, y):=u(c, y / a)$. For $(c, y, a) \in \mathbb{R}_{++}^{3}$ with $y<a$, define

$$
\eta^{a}(c, y):=-\frac{\partial U^{a}(c, y)}{\partial y} / \frac{\partial U^{a}(c, y)}{\partial c} .
$$

The following is the standard agent monotonicity condition introduced by Mirrlees (1971) (see also Seade (1982) and Myles (1995, p. 136)).

Definition 4. A utility function $u \in \mathscr{U}$ satisfies agent monotonicity if $\eta^{a}(c, y) \geq \eta^{a^{\prime}}(c, y)$ for each $(c, y) \in \mathbb{R}_{+}^{2}$ and $0<a<a^{\prime}$ with $y<a$.

The set of all the members of $\mathscr{U}$ satisfying agent monotonicity is denoted by $\mathscr{U}^{*}{ }^{12}$

For each $(a, b) \in \mathbb{R}_{++} \times \mathbb{R}_{+}$, consider the problem

$$
\max _{l \in[0,1]} u(a l+b, l) .
$$

This is the problem faced by an $a$-agent who receives a subsidy $b$. Since $u$ is strictly quasiconcave on $\mathbb{R}_{++} \times[0,1)$, for each $(a, b) \in \mathbb{R}_{++} \times \mathbb{R}_{+}$, there is a unique solution $l^{u}(a, b)$ to (7). For given $b \geq 0$, the derivative of the map $a \mapsto l^{u}(a, b)$ exists for all but at most one $a>0$ (see Carbonell-Nicolau and Llavador (2018)).

For $(a, b) \in \mathbb{R}_{++} \times \mathbb{R}_{+}$, define

$$
\zeta^{u}(a, b):=\frac{\partial\left(a l^{u}(a, b)+b\right)}{\partial a} \cdot \frac{a}{a l^{u}(a, b)+b} ;
$$

this is the elasticity of income with respect to ability at ability level $a$ and subsidy $b$.

Given $b \geq 0$ and $R \subseteq[0,1)$, let $\mathscr{U}(b, R)$ be the set of all $u \in \mathscr{U}^{*}$ satisfying the following condition:

$$
\zeta^{u}\left((1-r) a, b^{\prime}\right) \leq \zeta^{u}(a, 0), \quad \text { for all }\left(a, b^{\prime}, r\right) \in \mathbb{R}_{++} \times[b,+\infty) \times R .
$$

In this section, we restrict attention to the class of piecewise linear tax schedules in $\mathscr{T}$.

Definition 5. A tax schedule $T \in \mathscr{T}$ is a $(K+1)$-bracket piecewise linear tax schedule if

$$
T(y):=\left\{\begin{array}{lc}
-\alpha_{0}+t_{0} y & \text { if } 0=\bar{y}_{0} \leq y \leq \bar{y}_{1}, \\
-\alpha_{0}+t_{0} \bar{y}_{1}+t_{1}\left(y-\bar{y}_{1}\right) & \text { if } \bar{y}_{1}<y \leq \bar{y}_{2}, \\
\vdots & \vdots \\
-\alpha_{0}+t_{0} \bar{y}_{1}+t_{1}\left(\bar{y}_{2}-\bar{y}_{1}\right)+\cdots+t_{K-1}\left(\bar{y}_{K}-\bar{y}_{K-1}\right)+t_{K}\left(y-\bar{y}_{K}\right) & \text { if } \bar{y}_{K}<y,
\end{array}\right.
$$

where $\alpha_{0} \geq 0, K \in \mathbb{Z}_{+}, t_{k} \in[0,1)$ for each $k \in\{0, \ldots, K\}, t_{k} \neq t_{k+1}$ whenever $k \in\{0, \ldots, K-1\}$ and $K \geq 1$, and $0=\bar{y}_{0}<\cdots<\bar{y}_{K}$.

\footnotetext{
${ }^{12}$ The set $\mathscr{U}^{*}$ contains the standard utility functions used in the literature (see Carbonell-Nicolau and Llavador, 2018).
} 

tuple

A generic $(K+1)$-bracket piecewise linear tax schedule is completely determined by a

$$
\left(\alpha_{0}, \boldsymbol{t}, \overline{\boldsymbol{y}}\right)=\left(\alpha_{0},\left(t_{0}, \ldots, t_{K}\right),\left(\bar{y}_{0}, \ldots, \bar{y}_{K}\right)\right) .
$$

For $K \in \mathbb{Z}_{+}$, the set of $(K+1)$-bracket piecewise linear tax schedules is denoted by $\mathscr{T}_{K}$, and the set of all piecewise linear tax schedules in $\mathscr{T}$ is defined as

$$
\mathscr{T}^{*}:=\bigcup_{K=1}^{\infty} \mathscr{T}_{K}
$$

The following notion of progressivity plays a central role in the results of this section.

Definition 6. A tax schedule $T \in \mathscr{T}$ is marginal-rate progressive if it is a convex function.

In words, a tax schedule is marginal-rate progressive if it exhibits nondecreasing marginal tax rates on income. It is easy to see that a tax schedule $T \in \mathscr{T}$ is marginal-rate progressive only if it is average-rate progressive (recall Definition 3), but the converse assertion is not generally true.

The set of all marginal-rate progressive tax schedules in $\mathscr{T}^{*}$ is denoted by $\mathscr{T}_{m \text {-prog }}^{*}$.

We now define the following subclasses of $\mathscr{T}_{m-p r o g}^{*}$. Given $b \geq 0$ and $\left(R_{k}\right)_{k=0}^{\infty}$ with $R_{k} \subseteq[0,1)$ for all $k$, let

$$
\mathscr{T}_{m-p r o g}^{*}\left(b,\left(R_{k}\right)\right):=\bigcup_{K=0}^{\infty}\left\{\left(\alpha_{0}, \boldsymbol{t}, \overline{\boldsymbol{y}}\right) \in \mathscr{T}_{m-\operatorname{prog}}^{*} \cap \mathscr{T}_{K}: \alpha_{0} \geq b \text { and }\left(t_{0}, \ldots, t_{K}\right) \in R_{0} \times \cdots \times R_{K}\right\} .
$$

In words, $\mathscr{T}_{m \text {-prog }}^{*}\left(b,\left(R_{k}\right)\right)$ is the set of all marginal-rate progressive piecewise linear tax schedules that endow all agents with a subsidy of at least $b$ and whose $(k+1)$-th bracket's marginal tax rate $t_{k}(k=0,1, \ldots)$ is restricted within the subinterval $R_{k}$.

Note that for $b=0$ and $\left(R_{k}\right)=([0,1),[0,1), \ldots), \mathscr{T}_{m \text {-prog }}^{*}\left(b,\left(R_{k}\right)\right)$ is simply the set $\mathscr{T}_{m \text {-prog }}^{*}$.

When incomes are determined endogenously, the analogue of Definition 1, i.e., the notion of inequality reducing tax schedule, is formulated as follows.

Definition 7. Given $u \in \mathscr{U}$, a tax schedule $T \in \mathscr{T}^{*}$ is income inequality reducing with respect to $u$, denoted as $u$-iir, if the post-tax income distribution

$$
\left(x^{u}\left(a_{1}, T\right), \ldots, x^{u}\left(a_{n}, T\right)\right)
$$

Lorenz dominates the income distribution in the absence of taxation

$$
\left(y^{u}\left(a_{1}, 0\right), \ldots, y^{u}\left(a_{n}, 0\right)\right)
$$

for every ability distribution $\left(a_{1}, \ldots, a_{n}\right) \in \mathscr{A}_{n}$ and every pre-tax and post-tax income functions $y^{u}$ and $x^{u}$.

The following lemmas, proved in Carbonell-Nicolau and Llavador (2018), are instrumental for the proofs of our results. Lemma 1 is a well-known monotonicity result (see Theorem 1 in Mirrlees (1971)). Lemma 2 provides a characterization of an inequality reducing tax schedule in terms of pre-tax and post-tax income ratios. ${ }^{13}$

Lemma 1. Let $u \in \mathscr{U}^{*}$ and $T \in \mathscr{T}$. For every pre-tax and post-tax income functions $y^{u}$ and $x^{u}$, the maps $a \mapsto y^{u}(a, T)$ and $a \mapsto x^{u}(a, T)$ are nondecreasing on $\mathbb{R}_{++}$. Moreover, given $T \in \mathscr{T}$, there is a unique solution to (6) for all $a>0$, except for a set of measure zero.

\footnotetext{
${ }^{13}$ Lemma 2 is analogous to Lemma 1 in Jakobsson (1976), Proposition 2.1 in Moyes (1994), and Lemma 2 in Ebert and Moyes (2007).
} 
Lemma 2. Given $u \in \mathscr{U}^{*}$, a tax schedule $T \in \mathscr{T}$ is $u$-iir if and only if for any ability distribution $\boldsymbol{a} \in \mathscr{A}_{n}$, and for any pre-tax and post-tax income functions $y^{u}$ and $x^{u}$,

$$
\frac{x^{u}\left(a_{i}, T\right)}{y^{u}\left(a_{i}, 0\right)} \geq \frac{x^{u}\left(a_{i+1}, T\right)}{y^{u}\left(a_{i+1}, 0\right)} \quad \forall i \in\{1, \ldots, n-1\} .
$$

Remark 2. It follows from Lemma 1 that, under the agent monotonicity condition (Definition 4), in both cases the distribution vector coordinates in (8) and (9) are arranged in increasing order. In addition, the assumption that there exists $l>0$ such that $u(c, l)>u(\mathbf{0})$ whenever $c>0$ guarantees that $y^{u}\left(a_{1}, 0\right)$ is positive. Similarly, because the right derivative of any tax schedule in $\mathscr{T}^{*}$ is strictly less than unity, the last assumption also implies that $x^{u}\left(a_{1}, 0\right)$ is positive.

For $u \in \mathscr{U}^{*}$, the set of all tax schedules $T$ in $\mathscr{T}^{*}$ that are $u$-iir is denoted by $\mathscr{T}_{u \text {-iir }}^{*}$

The following characterization of income tax progressivity in the presence of disincentive effects of taxation on work effort is analogous to that for the case of exogenous income given in Theorem 1.

Theorem 3 (Carbonell-Nicolau and Llavador (forthcoming)). Given $u \in \mathscr{U}^{*}, b \geq 0$, and $\left(R_{k}\right)_{k=1}^{\infty}$ with $R_{k} \subseteq[0,1)$ for each $k$,

$$
\left[\mathscr{T}_{u-i i r}^{*} \subseteq \mathscr{T}_{m-p r o g}^{*}\right] \quad \text { and } \quad\left[\mathscr{T}_{m-p r o g}^{*}\left(b,\left(R_{k}\right)\right) \subseteq \mathscr{T}_{u-i i r}^{*} \Longleftrightarrow u \in \mathscr{U}\left(b, \bigcup_{k} R_{k}\right)\right]
$$

The bracketed containment asserts that inequality reducing tax schedules are necessarily marginal-rate progressive. The bracketed equivalence states that the members of the set $\mathscr{T}_{m-\text { prog }}^{*}\left(b,\left(R_{k}\right)\right)$ of all marginal-rate progressive tax schedules in $\mathscr{T}_{m \text {-prog }}^{*}$ whose intercept $\alpha_{0}$ is greater than or equal to $b$, and whose $k$-th marginal tax rate $t_{k}$ lies in $R_{k}$ (for each bracket $k$ ), are all inequality reducing if and only if $u \in \mathscr{U}\left(b, \cup_{k} R_{k}\right)$, i.e., if and only if the elasticity of income with respect to ability satisfies

$$
\zeta^{u}\left((1-r) a, b^{\prime}\right) \leq \zeta^{u}(a, 0), \quad \text { for all }\left(a, b^{\prime}, r\right) \in \mathbb{R}_{++} \times[b,+\infty) \times\left(\bigcup_{k} R_{k}\right) .
$$

The reader is referred to Carbonell-Nicolau and Llavador (forthcoming) for an interpretation of condition (10) based on a decomposition of the inequality in (10) into two conditions on the wage elasticity of income, each capturing different aspects of the transition between before-tax and after-tax income distributions.

In the special case when the lower bound on the intercept $\alpha_{0}$ of a tax schedule is zero and the marginal tax rates $t_{k}$ can take values anywhere in the interval $[0,1)$, Theorem 3 immediately gives the following result, which was first proven in Carbonell-Nicolau and Llavador (2018, Corollary 3).

Corollary 2. Given $u \in \mathscr{U}^{*}, \mathscr{T}_{u-i i r}^{*}=\mathscr{T}_{m-p r o g}^{*}$ if and only if $u \in \mathscr{U}(0,[0,1))$.

Next, we turn to the principle of 'bipolarization reducing taxation,' i.e., the analogue of Definition 2, in the presence of endogenous income.

Definition 8. Given $u \in \mathscr{U}$, a tax schedule $T \in \mathscr{T}^{*}$ is income bipolarization reducing with respect to $u$, denoted as $u$-bpr, if the post-tax income distribution

$$
\left(x^{u}\left(a_{1}, T\right), \ldots, x^{u}\left(a_{n}, T\right)\right)
$$


is less polarized, according to the preorder $\succcurlyeq_{R B}$, than the income distribution in the absence of taxation,

$$
\left(y^{u}\left(a_{1}, 0\right), \ldots, y^{u}\left(a_{n}, 0\right)\right),
$$

for every ability distribution $\left(a_{1}, \ldots, a_{n}\right) \in \mathscr{A}_{n}$ and every pre-tax and post-tax income functions $y^{u}$ and $x^{u} .14$

The following result shows that, also in the case of endogenous income, there is no tradeoff between inequality and bipolarization when one considers the principles of taxation in Definition 7 and Definition 8.

Given $u \in \mathscr{U}^{*}$, the set of all tax schedules $T$ in $\mathscr{T}^{*}$ that are $u$-bpr is denoted by $\mathscr{T}_{u \text {-bpr }}^{*}$

Theorem 4 asserts that the set of all inequality reducing tax schedules coincides with the set of all bipolarization reducing tax schedules.

Theorem 4. Given $u \in \mathscr{U}^{*}, \mathscr{T}_{u-i i r}^{*}=\mathscr{T}_{u-b p r}^{*}$

Proof. Suppose that $u \in \mathscr{U}^{*}$.

$\left[\mathscr{T}_{u-b p r}^{*} \subseteq \mathscr{T}_{u-i i r}^{*}.\right]$ Take $T \in \mathscr{T}_{u-b p r}^{*}$ and $\boldsymbol{a}=\left(a_{1}, \ldots, a_{n}\right) \in \mathscr{A}_{n}$. Choose any pair $a_{i}$ and $a_{j}$ with $a_{i}<a_{j}$. Let $\boldsymbol{a}^{\prime}=\left(a_{1}^{\prime}, \ldots, a_{n}^{\prime}\right) \in \mathscr{A}_{n}$ satisfy $a_{m-1}^{\prime}:=a_{i}<a_{m}^{\prime}<a_{j}=: a_{m+1}^{\prime}$. Because $T$ is $u$-bpr (Definition 8 and (1)),

$$
\begin{aligned}
& \frac{1}{n y^{u}\left(a_{m}^{\prime}, 0\right)}\left(y^{u}\left(a_{m}^{\prime}, 0\right)-y^{u}\left(a_{m-1}^{\prime}, 0\right)\right) \geq \frac{1}{n x^{u}\left(a_{m}^{\prime}, T\right)}\left(x^{u}\left(a_{m}^{\prime}, T\right)-x^{u}\left(a_{m-1}^{\prime}, T\right)\right), \\
& \frac{1}{n y^{u}\left(a_{m}^{\prime}, 0\right)}\left(y^{u}\left(a_{m+1}^{\prime}, 0\right)-y^{u}\left(a_{m}^{\prime}, 0\right)\right) \geq \frac{1}{n x^{u}\left(a_{m}^{\prime}, T\right)}\left(x^{u}\left(a_{m+1}^{\prime}, T\right)-x^{u}\left(a_{m}^{\prime}, T\right)\right) .{ }^{15}
\end{aligned}
$$

Arranging terms yields

$$
\begin{aligned}
& \frac{y^{u}\left(a_{m-1}^{\prime}, 0\right)}{y^{u}\left(a_{m}^{\prime}, 0\right)} \leq \frac{x^{u}\left(a_{m-1}^{\prime}, T\right)}{x^{u}\left(a_{m}^{\prime}, T\right)}, \\
& \frac{y^{u}\left(a_{m+1}^{\prime}, 0\right)}{y^{u}\left(a_{m}^{\prime}, 0\right)} \geq \frac{x^{u}\left(a_{m+1}^{\prime}, T\right)}{x^{u}\left(a_{m}^{\prime}, T\right)},
\end{aligned}
$$

and so it follows that

$$
\frac{x^{u}\left(a_{i}, T\right)}{y^{u}\left(a_{i}, 0\right)}=\frac{x^{u}\left(a_{m-1}^{\prime}, T\right)}{y^{u}\left(a_{m-1}^{\prime}, 0\right)} \geq \frac{x^{u}\left(a_{m}^{\prime}, T\right)}{y^{u}\left(a_{m}^{\prime}, 0\right)} \geq \frac{x^{u}\left(a_{m+1}^{\prime}, T\right)}{y^{u}\left(a_{m+1}^{\prime}, 0\right)}=\frac{x^{u}\left(a_{j}, T\right)}{y^{u}\left(a_{j}, 0\right)} .
$$

Since $a_{i}$ and $a_{j}$ were arbitrary coordinates in $\boldsymbol{a}$, it follows from Lemma 2 that $T \in \mathscr{T}_{u \text {-iir }}^{*}$, as we sought.

$\left[\mathscr{T}_{u-i i r}^{*} \subseteq \mathscr{T}_{u-b p r}^{*}.\right]$ Take $T \in \mathscr{T}_{u-i i r}^{*}$ and $\boldsymbol{a}=\left(a_{1}, \ldots, a_{n}\right) \in \mathscr{A}_{n}$. Define $b_{i}:=\frac{x^{u}\left(a_{i}, T\right)}{y^{u}\left(a_{i}, 0\right)}$. Because $T \in \mathscr{T}_{u \text {-iir }}^{*}$, it follows from Lemma 2 that $b_{i} \geq b_{j}$ for all $i<j$.

Observe that we can write, for each $i$,

$$
\frac{\left|x^{u}\left(a_{m}, T\right)-x^{u}\left(a_{i}, T\right)\right|}{n x^{u}\left(a_{m}, T\right)}=\frac{\left|b_{m} y^{u}\left(a_{m}, 0\right)-b_{i} y^{u}\left(a_{i}, 0\right)\right|}{n b_{m} y^{u}\left(a_{m}, 0\right)}=\frac{\left|y^{u}\left(a_{m}, 0\right)-\frac{b_{i}}{b_{m}} y^{u}\left(a_{i}, 0\right)\right|}{n y^{u}\left(a_{m}, 0\right)} .
$$

Consider first $i<m$. Then $\frac{b_{i}}{b_{m}} \geq 1$. Consequently, from (11) and the monotonicity of $x^{u}$ and $y^{u}$ in $a$ (Lemma 1), one obtains

$$
\frac{x^{u}\left(a_{m}, T\right)-x^{u}\left(a_{i}, T\right)}{n x^{u}\left(a_{m}, T\right)}=\frac{y^{u}\left(a_{m}, 0\right)-\frac{b_{i}}{b_{m}} y^{u}\left(a_{i}, 0\right)}{n y^{u}\left(a_{m}, 0\right)} \leq \frac{y^{u}\left(a_{m}, 0\right)-y^{u}\left(a_{i}, 0\right)}{n y^{u}\left(a_{m}, 0\right)} .
$$

\footnotetext{
${ }^{14}$ The function $R B$ that characterizes the preorder $\succcurlyeq_{R B}$ is also well defined in the endogenous income case, since median incomes are strictly positive. See Remark 2.

${ }^{15}$ By Lemma 1, the maps $a \mapsto y^{u}(a, T)$ and $a \mapsto x^{u}(a, T)$ are nondecreasing in $a$ on $\mathbb{R}_{++}$.
} 
Similarly, for $i>m, \frac{b_{i}}{b_{m}} \leq 1$ and

$$
\frac{x^{u}\left(a_{i}, T\right)-x^{u}\left(a_{m}, T\right)}{n x^{u}\left(a_{m}, T\right)}=\frac{\frac{b_{i}}{b_{m}} y^{u}\left(a_{i}, 0\right)-y^{u}\left(a_{m}, 0\right)}{n y^{u}\left(a_{m}, 0\right)} \leq \frac{y^{u}\left(a_{i}, 0\right)-y^{u}\left(a_{m}, 0\right)}{n y^{u}\left(a_{m}, 0\right)} .
$$

From (12) and (13), it follows that

$$
R B\left(\left(y^{u}\left(a_{1}, 0\right), \ldots, y^{u}\left(a_{n}, 0\right)\right), \alpha\right) \geq R B\left(\left(x^{u}\left(a_{1}, T\right), \ldots, x^{u}\left(a_{n}, T\right)\right), \alpha\right) \text { if } \alpha=\frac{j}{n} \text { for } j \in\{1, \ldots, n\},
$$

and, consequently,

$$
R B\left(\left(y^{u}\left(a_{1}, 0\right), \ldots, y^{u}\left(a_{n}, 0\right)\right), \alpha\right) \geq R B\left(\left(x^{u}\left(a_{1}, T\right), \ldots, x^{u}\left(a_{n}, T\right)\right), \alpha\right), \quad \text { for all } \alpha \in[0,1],
$$

implying that

$$
\left(x^{u}\left(a_{1}, T\right), \ldots, x^{u}\left(a_{n}, T\right)\right) \preccurlyeq R B\left(y^{u}\left(a_{1}, 0\right), \ldots, y^{u}\left(a_{n}, 0\right)\right) .
$$

Since $\boldsymbol{a}$ was arbitrary in $\mathscr{A}_{n}$, we conclude that $T \in \mathscr{T}_{u \text {-bpr }}^{*}$.

Combining Theorem 3 and Theorem 4 gives the following result.

Corollary 3. Given $u \in \mathscr{U}^{*}, b \geq 0$, and $\left(R_{k}\right)_{k=1}^{\infty}$ with $R_{k} \subseteq[0,1)$ for each $k$,

$$
\left[\mathscr{T}_{u-i i r}^{*}=\mathscr{T}_{u-b p r}^{*} \subseteq \mathscr{T}_{m-p r o g}^{*}\right] \quad \text { and } \quad\left[\mathscr{T}_{m-p r o g}^{*}\left(b,\left(R_{k}\right)\right) \subseteq \mathscr{T}_{u-i i r}^{*}=\mathscr{T}_{u-b p r}^{*} \Longleftrightarrow u \in \mathscr{U}\left(b, \bigcup_{k} R_{k}\right)\right] \text {. }
$$

The second bracketed expression states that the members of the set $\mathscr{T}_{m \text {-prog }}^{*}\left(b,\left(R_{k}\right)\right)$ of all marginal-rate progressive tax schedules in $\mathscr{T}_{m \text {-prog }}^{*}$ whose intercept $\alpha_{0}$ is greater than or equal to $b$, and whose $k$-th marginal tax rate $t_{k}$ lies in $R_{k}$ (for each bracket $k$ ), are all inequality reducing and bipolarization reducing if and only if $u \in \mathscr{U}\left(b, \cup_{k} R_{k}\right)$, i.e., if and only if the elasticity of income with respect to ability satisfies

$$
\zeta^{u}\left((1-r) a, b^{\prime}\right) \leq \zeta^{u}(a, 0), \quad \text { for all }\left(a, b^{\prime}, r\right) \in \mathbb{R}_{++} \times[b,+\infty) \times\left(\bigcup_{k} R_{k}\right) .
$$

Theorem 4 and Corollary 3 yield the following refinement of Corollary 2.

Corollary 4. Given $u \in \mathscr{U}^{*}, \mathscr{T}_{u-i i r}^{*}=\mathscr{T}_{u-b p r}^{*}=\mathscr{T}_{m-p r o g}^{*}$ if and only if $u \in \mathscr{U}(0,[0,1))$.

Corollary 4 is the analogue of Corollary 1 in the presence of disincentive effects of work effort. It identifies the set of preferences for which taxes are marginal-rate progressive if and only if they are inequality reducing if and only if they are bipolarization reducing.

\section{Concluding remarks}

Motivated by the ongoing global trend of increasing income inequality and the evolution of a shrinking middle class in the developed world, we have explored the possibility of designing tax systems aimed at reducing income inequality and bipolarization. Using the well-known relative Lorenz preorder to compare inequality across income distributions, and a relative version of the standard Foster-Wolfson polarization preorder (Foster and Wolfson, 2010), as axiomatized in Chakravarty $(2009,2015)$, as a bipolarization measure, we have shown that a tax schedule is progressive if and only if it is inequality reducing if and only if it is bipolarization reducing. This characterization holds in spite of the fact that the inequality and bipolarization measures employed are fundamentally different in nature. By considering 
the cases of exogenous and endogenous income, we have distinguished between average and marginal rate progressivity as the relevant concept for each case.

We conclude with two comments. First, this paper focuses on the reduction of income inequality and bipolarization through the tax system. The focus on income addresses voiced concerns about the social and economic effects of a vanishing share of adults in middleincome households, combined with widening income inequality. Some authors have suggested welfare (as opposed to income) inequality as the right metric, and a similar argument could be made for the notion of bipolarization. As pointed out in Carbonell-Nicolau and Llavador (2018), this idea poses difficulties in that measures of dispersion and/or polarization have a marked cardinality component and are generally not invariant to order-preserving utility transformations.

Secondly, there is an extensive literature on social polarization, based on measures of conflict among groups along different dimensions (such as income, race, ethnicity, language, education, etc.) that goes beyond the measure of income bipolarization considered in this paper (see Duclos and Taptué (2015) and references therein). Potentially fruitful areas for further research include extensions of the present work to alternative social polarization measures.

\section{Appendix: Even population size}

In this section, we first define the bipolarization preorder $\succcurlyeq_{R B}$ for pairs of distributions in $Z_{n} \times Z_{n}$ whose population size $n$ is even. We then complete the proof of Theorem 2, dealing with the case when $\boldsymbol{z}$ is a member of $\mathcal{Z}_{n}$ with $n$ even.

When $n$ is even, the median income is not a coordinate in the corresponding income distribution vector, introducing notational complications. This affects the definition of the bipolarization function $R B$ and the proof of Theorem 2 .

Given an income distribution $\boldsymbol{z}=\left(z_{1}, \ldots, z_{n}\right)$ with $n$ even, the median income, $m(\boldsymbol{z})$, is taken to be the arithmetic mean of the $\left(\frac{n}{2}\right)-t h$ and the $\left(\frac{n}{2}+1\right)$-th components in $\left(z_{1}, \ldots, z_{n}\right)$ : $m(\boldsymbol{z}):=\frac{z_{n / 2}+z_{(n / 2)+1}}{2}$.

When $n$ is even, the relative bipolarization function, $R B(\boldsymbol{z}, \alpha)$, representing the normalized aggregate deviation from the median income, is defined as follows (refer to Figure 1).

Given $\alpha \in[0,1]$ and an income distribution $\boldsymbol{z} \in \mathcal{Z}_{n}$,

$R B(\boldsymbol{z}, \alpha):= \begin{cases}\frac{1}{n m(\boldsymbol{z})} \sum_{j \leq i<\frac{n}{2}}\left(m(\boldsymbol{z})-z_{i}\right) & \text { if } \alpha=\frac{j}{n} \text { for some } j \in\left\{1, \ldots, \frac{n}{2}\right\}, \\ \frac{1}{n m(\boldsymbol{z})} \sum_{\frac{n}{2}+1 \leq i \leq j}\left(z_{i}-m(\boldsymbol{z})\right) & \text { if } \alpha=\frac{j}{n} \text { for some } j \in\left\{\frac{n}{2}+1, \ldots, n\right\}, \\ 1 & \text { if } \alpha=0,\end{cases}$

and

$$
R B(\boldsymbol{z}, \alpha):=\left\{\begin{array}{lr}
\lambda R B\left(\boldsymbol{z}, \frac{j}{n}\right)+(1-\lambda) R B\left(\boldsymbol{z}, \frac{j+1}{n}\right) & \text { if } \alpha=\lambda\left(\frac{j}{n}\right)+(1-\lambda)\left(\frac{j+1}{n}\right), \lambda \in(0,1), \\
\lambda R B\left(\boldsymbol{z}, \frac{1}{2}\right) & \quad j \in\{0,1, \ldots, n-1\}, j \neq \frac{n}{2}, \\
\lambda R B\left(\boldsymbol{z}, \frac{1}{2}+\frac{1}{n}\right) & \text { if } \alpha=\lambda\left(\frac{1}{2}\right)+(1-\lambda)\left(\frac{1}{2}+\frac{1}{2 n}\right), \lambda \in[0,1),
\end{array}\right.
$$

\section{Completion of the proof of Theorem 2}

Proof. Suppose that $n$ (the size of the population) is even.

$\left[\mathscr{T}_{a-p r o g} \supseteq \mathscr{T}_{b p r}\right.$. $]$ Let $T \in \mathscr{T}_{b p r}$, and suppose that $T \notin \mathscr{T}_{a \text {-prog. }}$. Because $T$ is not average-rate progressive, there exist $\hat{\boldsymbol{z}} \in \mathcal{Z}_{n}$ and $\hat{z}_{i}, \hat{z}_{j}$ with $\hat{z}_{i}<\hat{z}_{j}$ such that

$$
\frac{\hat{z}_{j}-T\left(\hat{z}_{j}\right)}{\hat{z}_{j}}>\frac{\hat{z}_{i}-T\left(\hat{z}_{i}\right)}{\hat{z}_{i}} \text {. }
$$




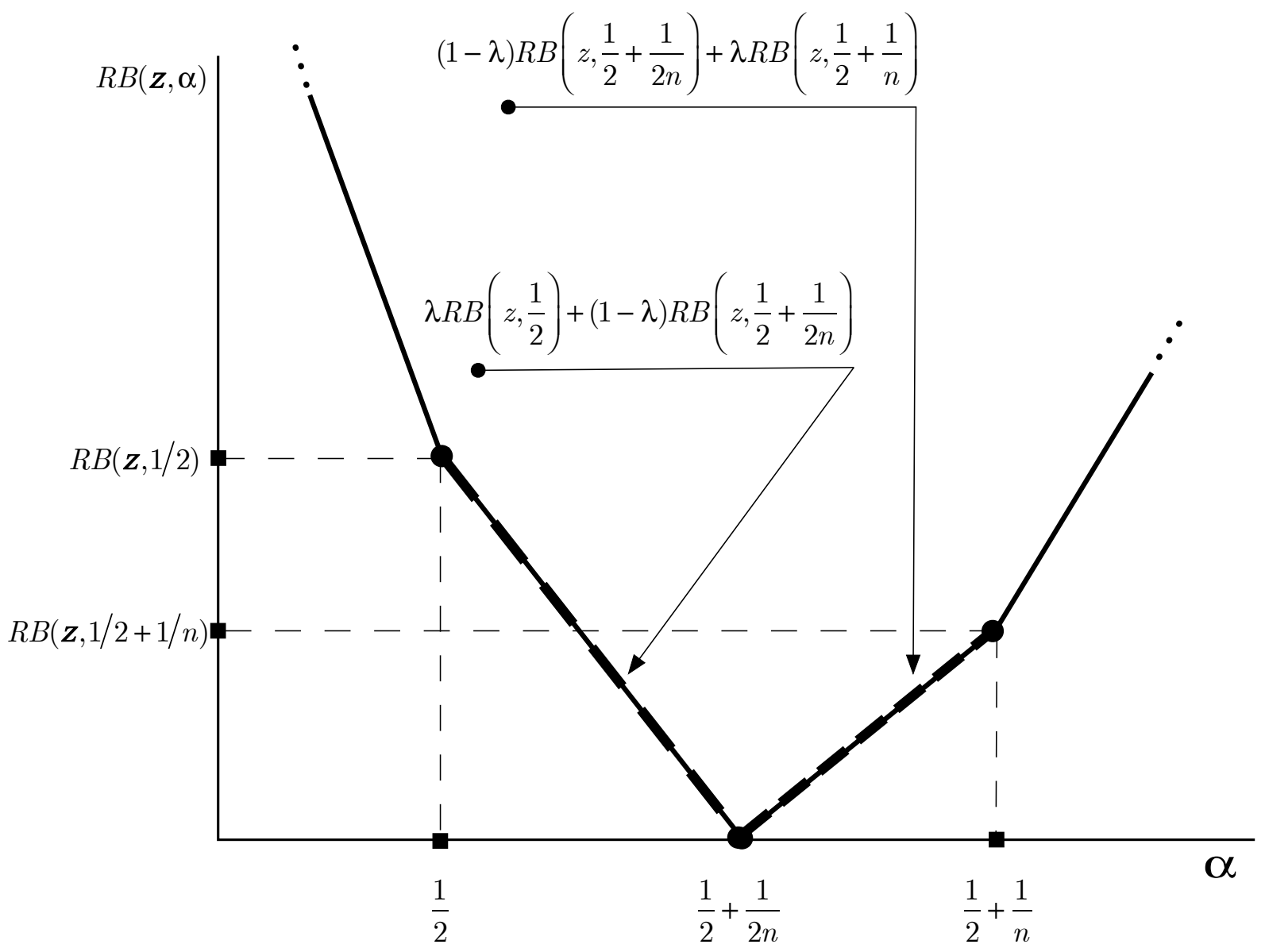

Figure 1: Relative Bipolarization Function when the population size $n$ is even. 
Now choose any income distribution $z=\left(z_{1}, \ldots, z_{n}\right)$ such that $z_{n / 2}:=\hat{z}_{i}<\hat{z}_{j}=: z_{(n / 2)+1}$. To lighten notation, define $T(\boldsymbol{z}):=\left(T\left(z_{1}\right), \ldots, T\left(z_{n}\right)\right)$. It is straightforward to verify that

$$
m(\boldsymbol{z}-T(\boldsymbol{z}))=\frac{z_{n / 2}-T\left(z_{n / 2}\right)+z_{(n / 2)+1}-T\left(z_{(n / 2)+1}\right)}{2}=m(\boldsymbol{z})-m(T(\boldsymbol{z})) .
$$

Consequently,

$$
R B\left(\boldsymbol{z}-T(\boldsymbol{z}), \frac{1}{2}\right)=\frac{m(\boldsymbol{z}-T(\boldsymbol{z}))-\left(z_{n / 2}-T\left(z_{n / 2}\right)\right)}{n \cdot m(\boldsymbol{z}-T(\boldsymbol{z}))}=\frac{1}{n}\left(1-\frac{z_{n / 2}-T\left(z_{n / 2}\right)}{m(\boldsymbol{z})-m(T(\boldsymbol{z}))}\right) .
$$

Observe that

$$
\frac{z_{n / 2}-T\left(z_{n / 2}\right)}{m(\boldsymbol{z})-m(T(\boldsymbol{z}))}=\frac{\hat{z}_{i}-T\left(\hat{z}_{i}\right)}{m(\boldsymbol{z})-m(T(\boldsymbol{z}))}=\frac{\hat{z}_{i}-T\left(\hat{z}_{i}\right)}{\frac{\hat{z}_{i}-T\left(\hat{z}_{i}\right)+\hat{z}_{j}-T\left(\hat{z}_{j}\right)}{2}}=2 \cdot \frac{1}{1+\frac{\hat{z}_{j}-T\left(\hat{z}_{j}\right)}{\hat{z}_{i}-T\left(\hat{z}_{i}\right)}}<2 \cdot \frac{1}{1+\frac{\hat{z}_{j}}{\hat{z}_{i}}}=\frac{\hat{z}_{i}}{m(\boldsymbol{z})},
$$

where the inequality uses (14). From (15) and (16), we see that

$$
R B\left(\boldsymbol{z}-T(\boldsymbol{z}), \frac{1}{2}\right)>\frac{1}{n}\left(1-\frac{\hat{z}_{i}}{m(\boldsymbol{z})}\right)=\frac{1}{n}\left(1-\frac{z_{n / 2}}{m(\boldsymbol{z})}\right)=R B\left(\boldsymbol{z}, \frac{1}{2}\right),
$$

contradicting the initial assumption that $T \in \mathscr{T}_{b p r}$.

$\left[\mathscr{T}_{\text {a-prog }} \subseteq \mathscr{T}_{b p r}\right.$.] Let $T \in \mathscr{T}_{a \text {-prog. }}$. We must show that $T \in \mathscr{T}_{b p r}$. Take $\boldsymbol{z} \in \mathcal{Z}_{n}$, and define $b_{i}:=\frac{z_{i}-T\left(z_{i}\right)}{z_{i}}$ for $i \in\{1, \ldots, n\}$ and $b(m):=\frac{m-m(T(\boldsymbol{z}))}{m}$, where $m:=m(\boldsymbol{z})=\left(z_{n / 2}+z_{(n / 2)+1}\right) / 2$.

Average-rate progressivity implies that $b_{i}$ is nonincreasing in $i$. Observe that we can write

$$
\left|\frac{(m-m(T(\boldsymbol{z})))-\left(z_{i}-T\left(z_{i}\right)\right)}{n(m-m(T(\boldsymbol{z})))}\right|=\frac{1}{n}\left|1-\frac{b_{i}}{b(m)} \frac{z_{i}}{m}\right|
$$

For all $i \leq n / 2$, we have that $1>\frac{b_{i}}{b(m)} \frac{z_{i}}{m} \geq \frac{z_{i}}{m}$. Therefore,

$$
\left|\frac{(m-m(T(\boldsymbol{z})))-\left(z_{i}-T\left(z_{i}\right)\right)}{n(m-m(T(\boldsymbol{z})))}\right|=\frac{1}{n}\left(1-\frac{b_{i}}{b(m)} \frac{z_{i}}{m}\right) \leq \frac{1}{n}\left(1-\frac{z_{i}}{m}\right)=\frac{m-z_{i}}{n m} .
$$

Similarly, for all $i>n / 2,1<\frac{b_{i}}{b(m)} \frac{z_{i}}{m} \leq \frac{z_{i}}{m}$ and, hence,

$$
\left|\frac{(m-m(T(\boldsymbol{z})))-\left(z_{i}-T\left(z_{i}\right)\right)}{n(m-m(T(\boldsymbol{z})))}\right|=\frac{1}{n}\left(\frac{b_{i}}{b(m)} \frac{z_{i}}{m}-1\right) \leq \frac{1}{n}\left(\frac{z_{i}}{m}-1\right)=\frac{z_{i}-m}{n m} .
$$

From (17) and (18), we conclude that

$$
R B\left(\left(z_{1}-T\left(z_{1}\right), \ldots, z_{n}-T\left(z_{n}\right)\right), \alpha\right) \leq R B(\boldsymbol{z}, \alpha), \quad \text { for all } \alpha \in[0,1],
$$

and consequently

$$
\left(z_{1}-T\left(z_{1}\right), \ldots, z_{n}-T\left(z_{n}\right)\right) \preccurlyeq_{R B} \boldsymbol{z} .
$$

Since $\boldsymbol{z}$ was arbitrary in $\mathcal{Z}_{n}$, we conclude that $T \in \mathscr{T}_{b p r}$.

\section{Completion of the proof of Theorem 4}

Proof. Suppose that $n$ (the population size) is even. Fix $u \in \mathscr{U}^{*}$.

$\left[\mathscr{T}_{u-b p r}^{*} \subseteq \mathscr{T}_{u-i i r}^{*}.\right]$ Take $T \in \mathscr{T}_{u-b p r}^{*}$ and $\boldsymbol{a}=\left(a_{1}, \ldots, a_{n}\right) \in \mathscr{A}_{n}$. Choose any pair $a_{i}$ and $a_{j}$ with $a_{i}<a_{j}$. Let $\boldsymbol{a}^{\prime}=\left(a_{1}^{\prime}, \ldots, a_{n}^{\prime}\right) \in \mathscr{A}_{n}$ satisfy $a_{n / 2}^{\prime}:=a_{i}<a_{j}=: a_{(n / 2)+1}^{\prime}$. Define

$$
m_{y}:=m\left(y^{u}\left(a_{1}, 0\right), \ldots, y^{u}\left(a_{n}, 0\right)\right)=\frac{y^{u}\left(a_{n / 2}, 0\right)+y^{u}\left(a_{(n / 2)+1}, 0\right)}{2}
$$


and

$$
m_{x}:=m\left(x^{u}\left(a_{1}, T\right), \ldots, x^{u}\left(a_{n}, T\right)\right)=\frac{x^{u}\left(a_{n / 2}, T\right)+x^{u}\left(a_{(n / 2)+1}, T\right)}{2} .
$$

Because $T$ is $u$-bpr,

$$
\begin{aligned}
\frac{1}{n \cdot m_{y}}\left(m_{y}-y^{u}\left(a_{n / 2}^{\prime}, 0\right)\right) & \geq \frac{1}{n \cdot m_{x}}\left(m_{x}-x^{u}\left(a_{n / 2}^{\prime}, T\right)\right), \\
\frac{1}{n \cdot m_{y}}\left(y^{u}\left(a_{(n / 2)+1}^{\prime}, 0\right)-m_{y}\right) & \geq \frac{1}{n \cdot m_{x}}\left(x^{u}\left(a_{(n / 2)+1}^{\prime}, T\right)-m_{x}\right) .{ }^{16}
\end{aligned}
$$

Arranging terms yields

$$
\begin{array}{r}
\frac{y^{u}\left(a_{n / 2}^{\prime}, 0\right)}{m_{y}} \leq \frac{x^{u}\left(a_{n / 2}^{\prime}, T\right)}{m_{x}}, \\
\frac{y^{u}\left(a_{(n / 2)+1}^{\prime}, 0\right)}{m_{y}} \geq \frac{x^{u}\left(a_{(n / 2)+1}^{\prime}, T\right)}{m_{x}},
\end{array}
$$

and so it follows that

$$
\frac{x^{u}\left(a_{i}, T\right)}{y^{u}\left(a_{i}, 0\right)}=\frac{x^{u}\left(a_{n / 2}^{\prime}, T\right)}{y^{u}\left(a_{n / 2}^{\prime}, 0\right)} \geq \frac{m_{x}}{m_{y}} \geq \frac{x^{u}\left(a_{(n / 2)+1}^{\prime}, T\right)}{y^{u}\left(a_{(n / 2)+1}^{\prime}, 0\right)}=\frac{x^{u}\left(a_{j}, T\right)}{y^{u}\left(a_{j}, 0\right)} .
$$

Since $a_{i}$ and $a_{j}$ were arbitrary coordinates in $\boldsymbol{a}$, it follows from Lemma 2 that $T \in \mathscr{T}_{u \text {-iir }}^{*}$, as we sought.

$\left[\mathscr{T}_{u-i i r}^{*} \subseteq \mathscr{T}_{u-b p r}^{*}.\right]$ Take $T \in \mathscr{T}_{u-i i r}^{*}$ and $\boldsymbol{a}=\left(a_{1}, \ldots, a_{n}\right) \in \mathscr{A}_{n}$. Define $b_{i}:=\frac{x^{u}\left(a_{i}, T\right)}{y^{u}\left(a_{i}, 0\right)}$. Because $T \in \mathscr{T}_{u \text {-iir }}^{*}$, it follows from Lemma 2 that $b_{i} \geq b_{j}$ for all $i<j$. that

Let $m_{y}$ and $m_{x}$ be defined as in (19) and (20), respectively, and put $b_{m}:=\frac{m_{x}}{m_{y}}$. We claim

$$
b_{1} \geq \cdots \geq b_{n / 2} \geq b_{m} \geq b_{(n / 2)+1} \geq \cdots \geq b_{n} .
$$

To see this, we only need to show that $b_{n / 2} \geq b_{m} \geq b_{(n / 2)+1}$, for we know that $b_{i} \geq b_{j}$ for all $i<j$. The inequality $b_{m} \geq b_{(n / 2)+1}$ can be expressed as

$$
\frac{\frac{x^{u}\left(a_{n / 2}, T\right)+x^{u}\left(a_{(n / 2)+1}, T\right)}{2}}{\frac{y^{u}\left(a_{n / 2}, 0\right)+y^{u}\left(a_{(n / 2)+1}, 0\right)}{2}} \geq \frac{x^{u}\left(a_{(n / 2)+1}, T\right)}{y^{u}\left(a_{(n / 2)+1}, 0\right)}
$$

which is equivalent to

$$
b_{n / 2}=\frac{x^{u}\left(a_{n / 2}, T\right)}{y^{u}\left(a_{n / 2}, 0\right)} \geq \frac{x^{u}\left(a_{(n / 2)+1}, T\right)}{y^{u}\left(a_{(n / 2)+1}, 0\right)}=b_{(n / 2)+1} .
$$

A similar argument yields $b_{n / 2} \geq b_{m}$. This establishes (21).

Next, observe that we can write, for each $i$,

$$
\frac{\left|m_{x}-x^{u}\left(a_{i}, T\right)\right|}{n \cdot m_{x}}=\frac{\left|b_{m} m_{y}-b_{i} y^{u}\left(a_{i}, 0\right)\right|}{n b_{m} m_{y}}=\frac{\left|m_{y}-\frac{b_{i}}{b_{m}} y^{u}\left(a_{i}, 0\right)\right|}{n \cdot m_{y}} .
$$

Consider first $i \leq \frac{n}{2}$. Then (21) gives $\frac{b_{i}}{b_{m}} \geq 1$. Consequently, from (22) and the monotonicity of $x^{u}$ and $y^{u}$ in $a$ (Lemma 1), one obtains

$$
\frac{m_{x}-x^{u}\left(a_{i}, T\right)}{n \cdot m_{x}}=\frac{m_{y}-\frac{b_{i}}{b_{m}} y^{u}\left(a_{i}, 0\right)}{n \cdot m_{y}} \leq \frac{m_{y}-y^{u}\left(a_{i}, 0\right)}{n \cdot m_{y}} .
$$

\footnotetext{
${ }^{16}$ By Lemma 1 , the maps $a \mapsto y^{u}(a, T)$ and $a \mapsto x^{u}(a, T)$ are nondecreasing in $a$ on $\mathbb{R}_{++}$.
} 
Similarly, for $i>m,(21)$ gives $\frac{b_{i}}{b_{m}} \leq 1$ and

$$
\frac{x^{u}\left(a_{i}, T\right)-m_{x}}{n \cdot m_{x}}=\frac{\frac{b_{i}}{b_{m}} y^{u}\left(a_{i}, 0\right)-m_{y}}{n \cdot m_{y}} \leq \frac{y^{u}\left(a_{i}, 0\right)-m_{y}}{n \cdot m_{y}} .
$$

From (23) and (24), it follows that

$$
R B\left(\left(y^{u}\left(a_{1}, 0\right), \ldots, y^{u}\left(a_{n}, 0\right)\right), \alpha\right) \geq R B\left(\left(x^{u}\left(a_{1}, T\right), \ldots, x^{u}\left(a_{n}, T\right)\right), \alpha\right) \text { if } \alpha=\frac{j}{n} \text { for } j \in\{1, \ldots, n\},
$$

and, consequently,

$$
R B\left(\left(y^{u}\left(a_{1}, 0\right), \ldots, y^{u}\left(a_{n}, 0\right)\right), \alpha\right) \geq R B\left(\left(x^{u}\left(a_{1}, T\right), \ldots, x^{u}\left(a_{n}, T\right)\right), \alpha\right), \quad \text { for all } \alpha \in[0,1],
$$

implying that

$$
\left(x^{u}\left(a_{1}, T\right), \ldots, x^{u}\left(a_{n}, T\right)\right) \preccurlyeq_{R B}\left(y^{u}\left(a_{1}, 0\right), \ldots, y^{u}\left(a_{n}, 0\right)\right) .
$$

Since $\boldsymbol{a}$ was arbitrary in $\mathscr{A}_{n}$, we conclude that $T \in \mathscr{T}_{u \text {-bpr }}^{*}$.

\section{References}

Aaberge, Rolf and Anthony B. Atkinson (2013) "The median as watershed," Statistics Norway Research Department Discussion Papers, No.749.

Atkinson, A.B. (1970) “On the measurement of inequality," Journal of Economic Theory, Vol. 2, pp. 244-263, DOI: http://dx.doi .org/10.1016/0022-0531(70)90039-6.

Atkinson, Anthony Barnes (2015) Inequality: What Can Be Done?: Belknap Press of Harvard University Press.

Banerjee, Abhijit V. and Esther Duflo (2008) "What is Middle Class about the Middle Classes around the World?, Journal of Economic Perspectives, Vol. 22, pp. 3-28, DOI: http: //dx.doi.org/10.1257/jep.22.2.3.

Birdsall, Nancy (2010) "The (Indispensable) Middle Class in Developing Countries," in Ravi Kanbur and Michael Spence eds. Equity and Growth in a Globalizing World, Washington D.C.: The International Bank for Reconstruction and Development/The World Bank, Chap. 7, pp. 157-187, DOI: http://dx.doi .org/10.1596/978-0-8213-8180-9.

Birdsall, Nancy, Carol Graham, and Stefano Pettinato (2000) "Stuck in Tunnel: Is Globalization Muddling the Middle?," DOI: http://dx.doi.org/10.2139/ssrn.277162, Brookings Institution Center Working Paper No. 14.

Bossert, W. and W. Schworm (2008) "A Class of Two-Group Polarization Measures," Journal of Public Economic Theory, Vol. 10, pp. 1169-1187, DOI: http://dx.doi .org/10.1111/j . 1467-9779.2008.00401.x.

Carbonell-Nicolau, Oriol and Humberto Llavador (2018) "Inequality reducing properties of progressive income tax schedules: The case of endogenous income," Theoretical Economics, Vol. 13, pp. 39-60, DOI: http://dx.doi.org/10.3982/TE2533.

(forthcoming) "Elasticity Determinants of Inequality Reducing Income Taxation," The Journal of Economic Inequality. 
Chakravarty, Satya R. (2009) Inequality, Polarization and Poverty: Springer Netherlands, pp.1-178, DOI: http://dx.doi.org/10.1007/978-0-387-79253-8.

Chakravarty, S.R. (2015) Inequality, Polarization and Conflict: An Analytical Study, Economic Studies in Inequality, Social Exclusion and Well-Being: Springer, DOI: http://dx . doi . org/10.1007/978-81-322-2166-1.

Deutsch, Joseph, Alessio Fusco, and Jacques Silber (2013) "The BIP Trilogy (Bipolarization, Inequality and Polarization): One Saga but Three Different Stories," Economics: The Open-Access, Open-Assessment E-Journal, Vol. 7, pp. 1-33, DOI: http://dx.doi .org/10 . 5018/economics-ejournal.ja.2013-22.

Duclos, Jean-Yves, Joan Esteban, and Debraj Ray (2004) "Polarization: Concepts, Measurement, Estimation," Econometrica, Vol. 72, pp. 1737-1772, DOI: http://dx.doi.org/10 . $1111 / \mathrm{j} .1468-0262.2004 .00552 . \mathrm{x}$.

Duclos, Jean-Yves and André-Marie Taptué (2015) "Polarization," Handbook of Income Distribution, Vol. 2, pp. 301-358, DOI: http://dx.doi .org/10.1016/B978-0-444-59428-0 . 00006-0.

Easterly, William (2001) "The Middle Class Consensus and Economic Development," Journal of Economic Growth, Vol. 6, pp. 317-335, DOI: http://dx.doi.org/10.1023/A : 1012786330095.

Ebert, U. and P. Moyes (2007) "Income taxation with labor responses," Journal of Public Economic Theory, Vol. 9, pp. 653-682, DOI: http://dx.doi.org/10.1111/j.1467-9779. 2007.00324.x.

Esteban, Joan and Debraj Ray (1994) "On the Measurement of Polarization," The Econometric Society, Vol. 62, pp. 819-851, DOI: http://dx.doi.org/10.2307/2951734.

(2012) “Comparing Polarization Measures," in Michelle R. Garfinkel and Stergios Skaperdas eds. The Oxford Handbook of the Economics of Peace and Conflict: Oxford University Press, pp. 1-27, DOI: http://dx.doi.org/10.1093/oxfordhb/9780195392777. 013.0007.

Fellman, J. (1976) "The effect of transformations of Lorenz curves," Econometrica, Vol. 44, pp. 823-824, DOI: http://dx.doi.org/10.2307/1913450.

Fortune (2018) “The Shrinking Middle Class," Fortune, URL: http://fortune.com/ longform/shrinking-middle-class/.

Foster, J.E. and M.C. Wolfson (2010) "Polarization and the decline of the middle class: Canada and the U.S.," Journal of Economic Inequality, Vol. 8, pp. 247-273, DOI: http: //dx.doi.org/10.1007/s10888-009-9122-7.

Jakobsson, U. (1976) "On the measurement of the degree of progression," Journal of Public Economics, Vol. 5, pp. 161-168, DOI: http://dx.doi.org/10.1016/0047-2727(76) 90066-9.

Jenkins, Stephen P. (1995) "Did the middle class shrink during the 1980s? UK evidence from kernel density estimates," Economics Letters, Vol. 49, pp. 407-413, DOI: http: //dx.doi.org/10.1016/0165-1765(95)00698-F. 
Le Breton, M., P. Moyes, and A. Trannoy (1996) "Inequality reducing properties of composite taxation," Journal of Economic Theory, Vol. 69, pp. 71-103, DOI: http://dx.doi .org/10 . $1006 /$ jeth. 1996.0038.

Milanovic, Branko (2016) Global Inequality: A New Approach for the Age of Globalization: Belknap Press of Harvard University Press.

Mirrlees, J.A. (1971) "Exploration in the theory of optimum income taxation," Review of Economic Studies, Vol. 38, pp. 175-208, DOI: http://dx.doi.org/10.2307/2296779.

Moyes, P. (1994) "Inequality reducing and inequality preserving transformations of incomes: Symmetric and individualistic transformations," Journal of Economic Theory, Vol. 63, pp. 271-298, DOI: http://dx.doi.org/10.1006/jeth.1994.1043.

Myles, G.D. (1995) Public Economics, Cambridge, UK: Cambridge University Press, DOI: http://dx.doi.org/10.1017/CB09781139170949.006.

Pew Research Center (2015) "The American Middle Class Is Losing Ground: No longer the majority and falling behind financially." (2017) "Middle Class Fortunes in Western Europe."

Piketty, Thomas (2014) Capital in the twenty-first century: Belknap Press of Harvard University Press.

Seade, J. (1982) "On the sign of the optimum marginal income tax," Review of Economic Studies, Vol. 49, pp. 637-643, DOI: http://dx.doi.org/10.2307/2297292.

Wang, Y.-Q. and K.-Y. Tsui (2000) "Polarization orderings and new classes of polarization indices," Journal of Public Economic Theory, Vol. 2, pp. 349-363, DOI: http://dx. doi . org/10.1111/1097-3923.00042.

Wolfson, Michael C. (1994) "When Inequalities Diverge," American Economic Review: Papers and Proceedings, Vol. 353, pp. 353-358. 